Check for updates

Cite this: RSC Adv., 2019, 9, 6054

Received 12th October 2018

Accepted 18th December 2018

DOI: $10.1039 / \mathrm{c} 8 \mathrm{ra0} 8458 \mathrm{k}$

rsc.li/rsc-advances

\section{Preparation of CaMgAl-LDHs and mesoporous silica sorbents derived from blast furnace slag for $\mathrm{CO}_{2}$ capture $\dagger$}

\author{
Haojie Jiang, ${ }^{a}$ Hongwei Guo, (DD *a Peng Li, ${ }^{\text {*a }}$ Yang Lib and Bingji Yan ${ }^{a}$
}

High volume blast furnace slag (BFS) resulting from iron-making activities has long been considered a burden for the environment. Despite considerable research efforts, attempts to convert BFS into high value-added products for environmental remediation are still challenging. In this study, calcium-magnesium-aluminium layered double hydroxides (CaMgAl-LDHs) and ordered mesoporous silica material (MCM-41) sorbents were simultaneously synthesized from BFS, and their $\mathrm{CO}_{2}$ adsorption performance was evaluated. Calcium (Ca), magnesium (Mg) and aluminium (Al) were selectively extracted from BFS using hydrochloric acid. Leaching conditions consisting of $2 \mathrm{~mol} \mathrm{~L}^{-1}$ acid concentration, $100{ }^{\circ} \mathrm{C}$ leaching temperature, $90 \mathrm{~min}$ leaching time and a solid-to-liquid ratio of $40 \mathrm{~g} \mathrm{~L}^{-1}$ achieved a high leaching ratio of $\mathrm{Ca}, \mathrm{Mg}$ and $\mathrm{Al}$ at $88.08 \%, 88.59 \%$ and $82.27 \%$, respectively. The silica-rich residue $\left(\mathrm{SiO}_{2}>98.6 \mathrm{wt} \%\right)$ generated from the leaching process could be used as a precursor for MCM-41 preparation. Chemical composition, surface chemical bonds, morphology and textural properties of the as-synthesized CaMgAl-LDHs and MCM-41 sorbents were determined. Both the CaMgAl-LDHs and MCM-41 sorbents were found to be thermally stable and exhibited comparable adsorption uptake and rates over $20 \mathrm{CO}_{2}$ adsorption/desorption cycles. This work demonstrated that a total solution for the utilisation of BFS can be achieved and the resulting valuable products, i.e. CaMgAl-LDHs and MCM-41 are promising sorbents for $\mathrm{CO}_{2}$ capture.

\section{Introduction}

One of the most significant environmental challenges faced by humans in the 21st century is global warming caused by the increase in carbon dioxide levels. ${ }^{1}$ In response to the issue of greenhouse gases, many countries have proposed a series of carbon emission reduction plans. Notably, research into options for the capture, utilisation and long-term storage of carbon dioxide has become a hot topic in the field of low-carbon and zero-carbon technologies, which include renewable energy, clean energy and carbon capture \& storage (CCS)..$^{1-5}$ (CCS) is being investigated as a potential option to capture $\mathrm{CO}_{2}$ at the source of generation from various industrial facilities, and to transport and separate the captured $\mathrm{CO}_{2}$ in storage areas. ${ }^{5-9}$

Iron and steel manufacturing are not only major energyconsuming industries but also major emitters of greenhouse gases. The generation of large amounts of solid waste including blast furnace slag (BFS) and steel slag (SS) has caused severe

${ }^{a}$ Shagang School of Iron and Steel, Soochow University, Suzhou 215021, P. R. China. E-mail: guohongwei@suda.edu.cn; lipeng@suda.edu.cn; Fax: +86-0512-62334926; Tel: +86-0512-62334926

${ }^{b}$ The State Key Laboratory of Refractories and Metallurgy, School of Materials and Metallurgy, Wuhan University of Science and Technology, Wuhan 430081, China

$\dagger$ Electronic supplementary information (ESI) available. See DOI: $10.1039 / \mathrm{c} 8 \mathrm{ra} 08458 \mathrm{k}$ environmental problems involving water and soil contamination, and local air pollution. ${ }^{10}$ To reduce or resolve these growing environmental concerns, many current research activities are focusing on the development of new waste management strategies such as the preparation of useful materials from waste. In the past ten years, mineral carbonation is the most dynamic and the fastest growing $\mathrm{CO}_{2}$ sequestration technology. In mineral carbonation, $\mathrm{CO}_{2}$ gas is stored by promoting the reaction of magnesium or calcium oxides in silicate minerals with carbon dioxide to form carbonates; ${ }^{4}$ BFS and SS from the steel industry contain a large number of alkaline oxides, such as $\mathrm{CaO}$ and $\mathrm{MgO}$, which can be used for $\mathrm{CO}_{2}$ capture. ${ }^{11}$

In Finland, Eloneva et $a l^{2-5}$ studied the possibility of utilizing SS for the production of pure calcium carbonate. They found that dilute acetic acid only selectively dissolved calcium from the steel slag. Tian $e t a l .^{12}$ proposed a process for simultaneously producing $\mathrm{CaO}$-based $\mathrm{CO}_{2}$ sorbents and high-quality iron ore from waste SS. The results showed that the extraction of calcium was always accompanied by the undesired dissolution of elemental impurities such as $\mathrm{Al}, \mathrm{Mg}$ and $\mathrm{Fe}$, resulting in decreased $\mathrm{CO}_{2}$ adsorption capacity.

As well as the intensive research activity on SS, BFS is also considered as valuable raw material in $\mathrm{CO}_{2}$ sequestration. Compared with SS, BFS is more greatly enriched in elemental Ca, $\mathrm{Mg}$, Si and $\mathrm{Al}$, which together account for around $90 \%$ of its total mass; this means that the aqueous extraction of BFS could 
potentially leads to less contamination. Seonhye Lee et $a .^{1}$ studied the indirect sequestration of $\mathrm{CO}_{2}$ using BFS as the raw material and achieved $49.76 \%$ extraction efficiency of $\mathrm{Ca}$ and 95.69\% carbonation efficiency using $\mathrm{NH}_{4} \mathrm{NO}_{3}$ under typical conditions $\left(2 \mathrm{~mol} \mathrm{~L}{ }^{-1}\right.$ solvent concentration, $30{ }^{\circ} \mathrm{C}$ reaction temperature, $60 \mathrm{~min}$ reaction time, $10 \mathrm{~g} \mathrm{~L}^{-1}$ solid-to-liquid ratio).

In their early research, Yasutaka Kuwahara et al. ${ }^{13}$ successfully synthesised a Ca-based layered double hydroxide (LDH) compound from BFS, and applied it in $\mathrm{CO}_{2}$ fixation. In their methodology, the hydrochloric acid leaching resulted in a precursor solution suited for LDH preparation and hydrated silica gel. Inspired by this result, in this paper, a facile method for the simultaneous preparation of (LDHs) and ordered mesoporous silica (MCM-41) materials from BFS is reported. The objectives of this research are to focus on: (i) clarifying the influence of acid leaching conditions on the dissolution behavior of BFS, and seeking optimised conditions for the selective and highly efficient dissolution of elemental calcium, magnesium and aluminium; (ii) making best use of the BFS through synthesising LDHs and MCM41 sorbents by recovering the leachate and residue after solvent extraction and subsequent structural characterisation, (iii) the evaluation of $\mathrm{CO}_{2}$ sequestration ability for both sorbents through adsorption-desorption measurements.

\section{Experimental}

\subsection{Materials and test facilities}

Water granulated blast furnace slag was received from the Shagang Steel Co., Ltd., China. The slag was crashed and ball

Table 1 Chemical composition of blast furnace slag A: measured by XRF analysis, B: by ICP-OES analysis

\begin{tabular}{llllllll}
\hline $\mathrm{Al}_{2} \mathrm{O}_{3}$ & $\mathrm{SiO}_{2}$ & $\mathrm{CaO}$ & $\mathrm{MgO}$ & $\mathrm{K}_{2} \mathrm{O}$ & $\mathrm{Fe}_{2} \mathrm{O}_{3}$ & $\mathrm{Na}_{2} \mathrm{O}$ & $\mathrm{MnO}$ \\
\hline $\begin{array}{l}\text { Composition } \\
\text { wt\% } 14.47\end{array}$ & 34.27 & 36.84 & 10.14 & 0.52 & 0.53 & 0.43 & 0.52 \\
& & & & & & & \\
$\begin{array}{l}\text { Composition } \\
\text { wt\% } 14.66\end{array}$ & 32.77 & 36.14 & 10.79 & $\mathrm{NA}$ & 0.26 & $\mathrm{NA}$ & $\mathrm{NA}$
\end{tabular}

milled to a particle size of less than $74 \mu \mathrm{m}$. The chemical composition of the BFS was analysed using X-ray fluorescence (XRF, SHIMADZU-EDX800, Japan), and the concentrations of $\mathrm{Ca}, \mathrm{Si}, \mathrm{Mg}$ and $\mathrm{Al}$ in the solution were measured using inductively coupled plasma-optic emission spectrometry (ICP-OES, Vista-MPX, Varian, USA). The composition ${ }^{\mathrm{A}}$ results from XRF quantitative measurements are shown in Table 1, revealing that the BFS was mainly composed of $36.84 \mathrm{wt} \% \mathrm{CaO}, 34.27 \mathrm{wt} \%$ $\mathrm{SiO}_{2}, 10.14$ wt $\% \mathrm{MgO}$ and $14.47 \mathrm{wt} \% \mathrm{Al}_{2} \mathrm{O}_{3}$, which together accounted for $95 \%$ of the total mass. Results of the ICP-OES analysis gave the composition ${ }^{B}$ of the solution, with these values used for estimating the leaching ratio of metal ions from the BFS.

The mineralogical phases were identified by X-ray diffraction (XRD, UltimaI VX, Rigaku, Japan) with $\mathrm{CuK} \alpha$ radiation, utilising a generator voltage of $40 \mathrm{kV}$ and tube current of $40 \mathrm{~mA}$. Smallangle X-ray scattering (SAXS) measurements were carried out at room temperature using a SAXSess $\mathrm{mc}^{2}$ (Anton Paar) instrument.

Surface functional groups were determined with Fourier transform infrared spectroscopy (Jasco FT-IR-4100) with $\mathrm{KBr}$ in the $1800-400 \mathrm{~cm}^{-1}$ region.

Morphologies were characterized by scanning electron microscope (SEM, SU5000, Hitachi, Japan) and a transmission electron microscope (TEM, TECNAI G2 F20, FEI, USA). Textural properties were investigated by $\mathrm{N}_{2}$ adsorption-desorption measurements using an ASAP 2000 instrument (Micromeritics, USA). Thermogravimetric analysis (TGA) was performed to evaluate thermal stability using a TGA-50/50H analyser (Shimadzu, Kyoto, Japan).

\subsection{Experimental methods}

2.2.1 Hydrochloric acid dissolution experiments. As illustrated in Fig. 1, extraction experiments were carried out in a $500 \mathrm{~mL}$ flat-bottomed flask glass reactor with a working volume of $200 \mathrm{~mL}$. A mechanical stirrer (Dragonlab® MS7H550-S, Dragon Laboratory Instruments Co. Ltd., Beijing, China) was installed at the center of the reactor and used to mix the slurry at $500 \mathrm{rpm}$. The glass reactor was placed in a temperature-controlled water bath to maintain a consistent

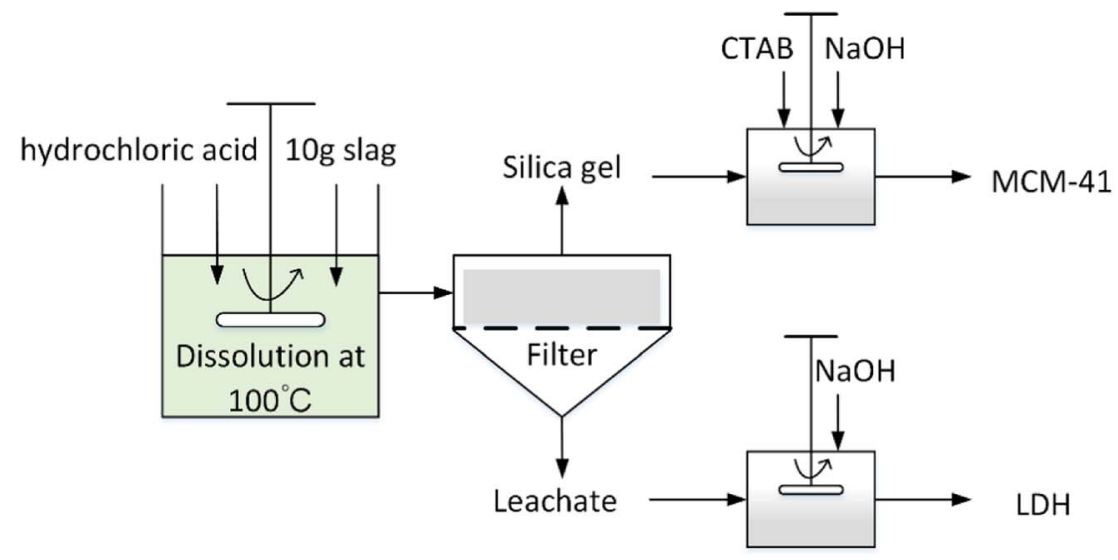

Fig. 1 Employed methodology for simultaneously producing LDHs and MCM-41 from blast furnace slag. 
reaction temperature. To avoid evaporation losses, the reactor was equipped with a condenser cooled with tap water.

BFS (10 g) was added to the reactor containing a specific concentration ( $0.5 \mathrm{M}, 1 \mathrm{M}, 2 \mathrm{M}$ or $3 \mathrm{M})$ of hydrochloric acid (11.74 M, Enox) at $100{ }^{\circ} \mathrm{C}$. To monitor the progression of the dissolution, $5 \mathrm{~mL}$ of aqueous solution was sampled using quantitative pipette at $5,10,20,40,60,80,100,120,140,160$ and $180 \mathrm{~min}$ after the slag was added.

The leaching ratio of a specific element was calculated by the following equation:

$$
\text { Leaching ratio }(\%)=\frac{C_{\mathrm{x}} V}{M_{\mathrm{s}} W_{\mathrm{x}}} \times 100
$$

Here, $C_{\mathrm{x}}\left(\mathrm{mg} \mathrm{L}^{-1}\right)$ represents the concentration of a selected element in the extracted aqueous solution, $V(\mathrm{~L})$ is the volume of aqueous solution, $M_{\mathrm{S}}(\mathrm{mg})$ denotes the mass of the slag and $W_{\mathrm{x}}$ (wt\%) is the elemental content in the slag.

2.2.2 Synthesis of LDHs. After the leaching process, the obtained leachate containing $\mathrm{Ca}^{2+}, \mathrm{Mg}^{2+}, \mathrm{Al}^{3+}$ can be used as precursor for LDHs synthesis. $\mathrm{NaOH}$ aqueous solution (2 M) was added dropwise into the leachate $(150 \mathrm{~mL})$ and the final $\mathrm{pH}$ adjusted to 12 . The resulting mixture was then aged at $80{ }^{\circ} \mathrm{C}$ for $18 \mathrm{~h}$ to enable crystallisation. The aged mixture was filtered and washed with deionised water several times until the $\mathrm{pH}$ was 7 . Finally, the obtained product was dried at $100{ }^{\circ} \mathrm{C}$ overnight.

2.2.3 Synthesis of MCM-41. The solid residue resulting from acid leaching was subjected to secondary acid leaching ( $2 \mathrm{M}$ acid concentration, $1 \mathrm{~h}$ of leaching at $100^{\circ} \mathrm{C}$ ) to remove impurities. The XRF results in Table 2 show that the secondary acid leaching yielded solid residue containing around $98.6 \mathrm{wt} \%$ of silica and could be utilised as a precursor for mesoporous silica preparation.

In a typical procedure, $n$-cetyltrimethylammonium bromide (CTAB, $1.457 \mathrm{~g})$ was dissolved in of deionised water $(60 \mathrm{~mL})$ at room temperature. Then, acid leaching residue $(1.2 \mathrm{~g})$ and $\mathrm{NaOH}(1 \mathrm{~g})$ were added to the CTAB aqueous solution. The mixture was stirred until a clear solution was obtained, following which $\mathrm{NaOH}$ or $\mathrm{HCl}$ solution was added dropwise to adjust the $\mathrm{pH}$ to 11 . The resulting solution was further stirred for another one hour, then placed in a Teflon-lined autoclave for hydrothermal treatment at $80{ }^{\circ} \mathrm{C}$ for $48 \mathrm{~h}$. After that, the slurry was filtered, washed repeatedly using deionised water and airdried overnight at $100{ }^{\circ} \mathrm{C}$. Finally, the as-synthesized silica powder was calcined at $550{ }^{\circ} \mathrm{C}$ in air for $6 \mathrm{~h}$.

2.2.4 Measurements of $\mathrm{CO}_{2}$ adsorption capacity. $\mathrm{CO}_{2}$ adsorption-desorption measurements of synthesized LDHs and MCM-41 materials were performed on a thermogravimetric analyser (CP-2000, Beijing). Precisely $10 \mathrm{mg}$ sample was activated by heating it to a desired temperature and maintaining the temperature for $30 \mathrm{~min}$ under $\mathrm{N}_{2}\left(50 \mathrm{~mL} \mathrm{~min}{ }^{-1}\right)$ before $\mathrm{CO}_{2}$ adsorption. The temperature was then adjusted to the adsorption temperature and the gas feed switched from $\mathrm{N}_{2}$ to $\mathrm{CO}_{2}$ with

Table 2 Chemical composition of the solid residue obtained from secondary acid leaching

$\begin{array}{llllllllll}\text { Composition } & \mathrm{SiO}_{2} & \mathrm{Al}_{2} \mathrm{O}_{3} & \mathrm{MgO} & \mathrm{TiO}_{2} & \mathrm{Fe}_{2} \mathrm{O}_{3} & \mathrm{SO}_{3} & \mathrm{MnO} & \mathrm{Cl}\end{array}$

$\begin{array}{llllllllll}\text { wt } \% & 98.581 & 0.094 & 0.048 & 0.017 & 0.013 & <0.01 & <0.01 & 0.689\end{array}$

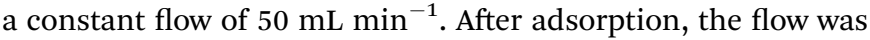
switched from $\mathrm{CO}_{2}$ to $\mathrm{N}_{2}$ and the temperature adjusted to and maintained at the activated temperature for $30 \mathrm{~min}$ for completion of one desorption. This experiment was repeated twenty times to investigate the stability of $\mathrm{CO}_{2}$ adsorption.

\section{Results and discussion}

\subsection{Leaching of BFS}

3.1.1 Effect of hydrochloric acid concentration. According to the results in Fig. 2, the dissolution of elemental $\mathrm{Ca}, \mathrm{Mg}, \mathrm{Al}$ and Si in BFS was strongly dependent on acid concentration. The leaching ratios of $\mathrm{Ca}, \mathrm{Mg}, \mathrm{Al}$ significantly improved when the acid concentration exceeded $1 \mathrm{M}$. Surprisingly the rate of dissolution of BFS in acid solution was extremely fast and the leaching ratios for these elements reached a within 5-10 min of initial contact; this suggested that the water-granulated BFS exhibits outstanding reactivity. In contrast, the dissolution behaviour of Si followed a different pattern. When higher concentrations of $2 \mathrm{M}$ and $3 \mathrm{M}$ were employed, the leaching ratio of Si was drastically reduced from $65 \%$ to $1.27 \%$ after $80 \mathrm{~min}$ and continuously decreased to nearly zero.

3.1.2 Effect of leaching temperature. Fig. 3 shows that increasing the temperature from 70 to $100{ }^{\circ} \mathrm{C}$ did not enhance the dissolution of $\mathrm{Ca}, \mathrm{Mg}, \mathrm{Al}$ and $\mathrm{Si}$; on the contrary, the leaching ratios of these elements all decreased. In particular, the leaching ratio of Si dropped dramatically to $1.27 \%$ at $100{ }^{\circ} \mathrm{C}$, which suggested that high temperature favours the formation of silica gel and consequently leads to decreased dissolution of Si. The newly forming silica gel with high surface area has the capability of caging metal ions, which may account for lower leaching ratios of $\mathrm{Ca}, \mathrm{Mg}$ and $\mathrm{Al}$ at higher temperatures.

3.1.3 Effects of the solid-to-liquid ratio. To study the effect of the solid-to-liquid $(\mathrm{S} / \mathrm{L})$ ratio on the leaching behavior, the acid solution (concentration and volume) was kept constant and the amount of BFS doped in the solution was varied, i.e. $6,8,10,12,14$ gram. As shown in Fig. 4, the general trend was that the leaching ratio of $\mathrm{Ca}, \mathrm{Mg}$, and $\mathrm{Al}$ increased as the $\mathrm{S} / \mathrm{L}$ ratio decreased. At a $\mathrm{S} / \mathrm{L}$ ratio of $40 \mathrm{~g} \mathrm{~L}^{-1}$, the highest leaching ratio of $\mathrm{Ca}, \mathrm{Mg}, \mathrm{Al}$ was achieved at $88.08 \%, 88.59 \%$ and $82.27 \%$, respectively. Meanwhile, the $\mathrm{S} / \mathrm{L}$ ratio had little effect on the dissolution behaviour of $\mathrm{Si}$.

3.1.4 Leaching selectivity. The degree of elemental selectivity was used to identify the optimised extraction conditions for subsequent synthesis of high purity LDHs and MCM-41 materials. As can be seen from Table 3, a leaching temperature of $100{ }^{\circ} \mathrm{C}$, acid concentration of $2 \mathrm{M}$ and $\mathrm{S} / \mathrm{L}$ ratio of $40 \mathrm{~g}$ $\mathrm{L}^{-1}$, yielded a satisfied elemental selectivity, that is the elemental selectivity for silicon was a minimum and high leaching ratio. Increase in the acid concentration resulted in the considerable decomposition of the amorphous silica phase within only a few minutes of leaching. Dissolved silicon presents as $\mathrm{Si}(\mathrm{OH})_{4}$, which is monomeric silica in an acidic solution. Once the monomeric concentration exceeds the saturation level, the discrete silica particles start to polymerise to into a gel. The above experimental results indicated that high temperature and long leaching times can promote the polymerisation of $\mathrm{Si}$ according to eqn (2) and (3): ${ }^{\mathbf{1 4}}$ 

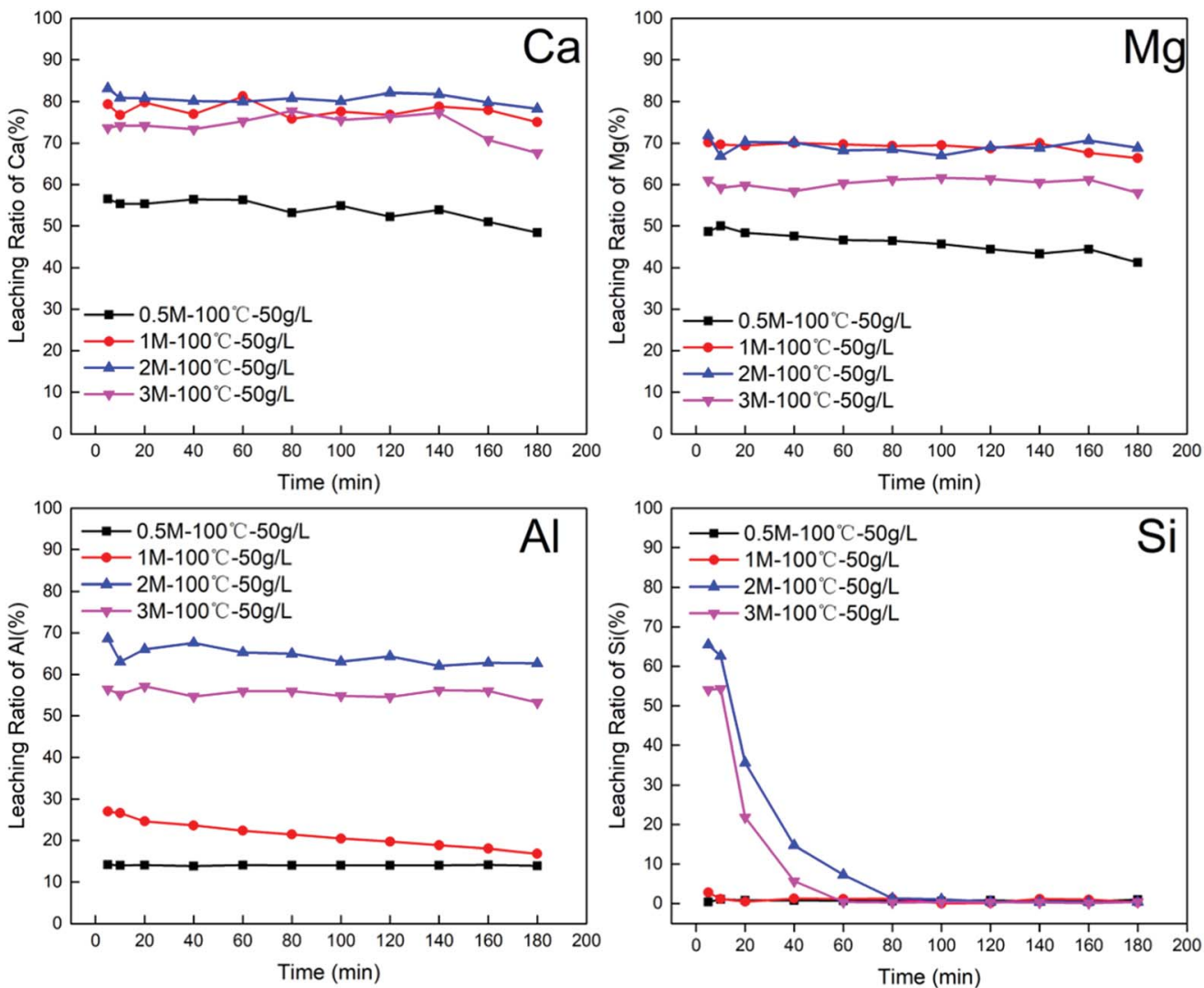

Fig. 2 Effect of the variation in the hydrochloric acid concentrations $(0.5 \mathrm{M}, 1 \mathrm{M}, 2 \mathrm{M}, 3 \mathrm{M})$ on the leaching ratio of Ca, Mg, $\mathrm{Al}$, Si at condition: temperature of $100{ }^{\circ} \mathrm{C}$, solid to liquid ratio of $50 \mathrm{~g} \mathrm{~L}^{-1}$.

$$
\begin{gathered}
\mathrm{Si}(\mathrm{OH})_{4}+\mathrm{Si}(\mathrm{OH})_{4} \rightarrow(\mathrm{HO})_{3} \mathrm{Si}-\mathrm{O}-\mathrm{Si}(\mathrm{OH})_{3}+\mathrm{H}_{2} \mathrm{O} \\
(\mathrm{HO})_{3} \mathrm{Si}-\mathrm{O}-\mathrm{Si}(\mathrm{OH})_{3} \rightarrow\left(\mathrm{SiO}_{2}\right)_{2}+3 \mathrm{H}_{2} \mathrm{O}
\end{gathered}
$$

(2) leachate solution: the molar ratio should meet the general requirements (between 2 and 4$)^{15}$ for the preparation of LDHs.

(3) The value of $n\left(\mathrm{M}^{2+}\right) / n\left(\mathrm{M}^{3+}\right)$ is strongly related to the hydrochloric acid concentration. With increased acid concentration, $n\left(\mathrm{M}^{2+}\right) / n\left(\mathrm{M}^{3+}\right)$ decreased, which suggests that the trivalent metal

Another important index that also needs to be considered is the molar ratio of divalent cations to trivalent cations in the

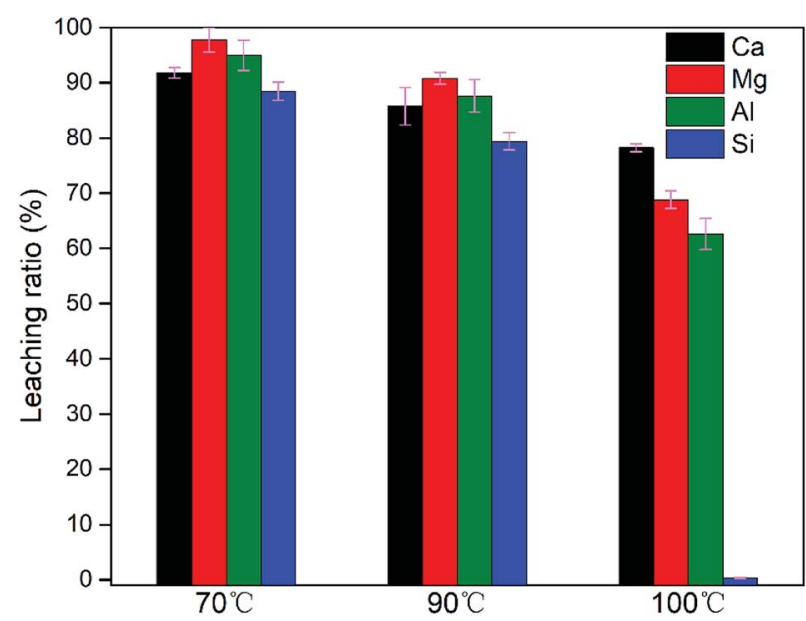

Fig. 3 Effect of leaching temperature $\left(70^{\circ} \mathrm{C}, 90^{\circ} \mathrm{C}, 100^{\circ} \mathrm{C}\right)$ on the leaching ratio of $\mathrm{Ca}, \mathrm{Mg}, \mathrm{Al}$, Si at condition: acid concentration of $2 \mathrm{M}$, the solid to liquid ratio of $50 \mathrm{~g} \mathrm{~L}^{-1}$, leaching time of $90 \mathrm{~min}$.

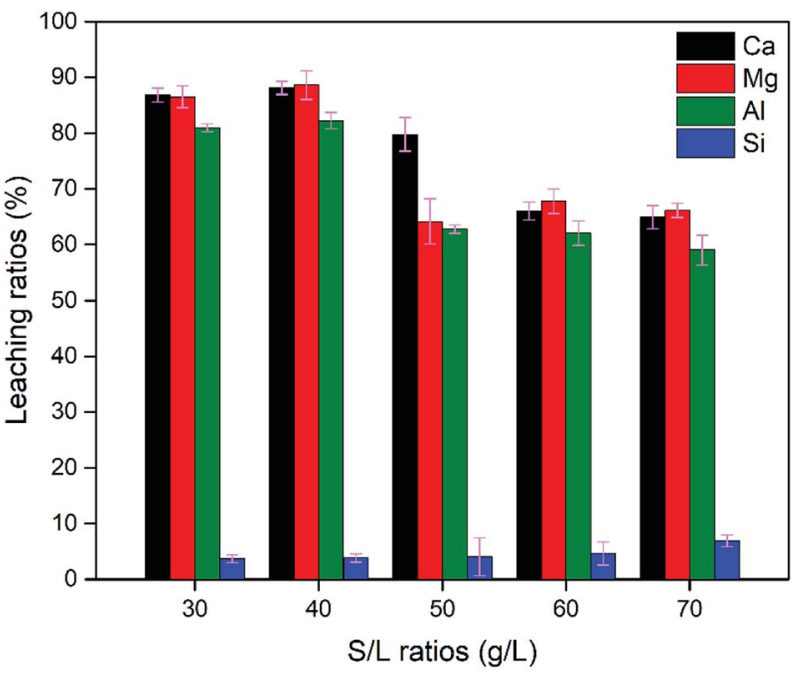

Fig. 4 Effect of the $S / L$ ratio $\left(30,40,50,60,70 \mathrm{~g} \mathrm{~L}^{-1}\right)$ on the leaching ratio of $\mathrm{Ca}, \mathrm{Mg}, \mathrm{Al}, \mathrm{Si}$ at condition: temperature of $100{ }^{\circ} \mathrm{C}$, acid concentration of $2 \mathrm{M}$, leaching time of $90 \mathrm{~min}$. 
Table 3 Elemental selectivity of four elements and $n\left(\mathrm{M}^{2+}\right) / n\left(\mathrm{M}^{3+}\right)$ in the leachate solution from different leaching conditions ${ }^{a}$

\begin{tabular}{|c|c|c|c|c|c|c|c|}
\hline $\begin{array}{l}\text { Concentration } \\
\text { of } \mathrm{HCl}(\mathrm{M})\end{array}$ & Temperature $\left({ }^{\circ} \mathrm{C}\right)$ & $\mathrm{S} / \mathrm{L}$ ratios $\left(\mathrm{g} \mathrm{L}^{-1}\right)$ & \multicolumn{4}{|c|}{ Elemental selectivity (\%) } & $n\left(\mathrm{M}^{2+}\right) / n\left(\mathrm{M}^{3+}\right)$ \\
\hline 1 & 100 & 50 & 69.36 & 23.59 & 6.81 & 0.24 & 13.65 \\
\hline 2 & 100 & 50 & 58.99 & 20.05 & 20.73 & 0.23 & 3.81 \\
\hline 3 & 100 & 50 & 59.55 & 19.67 & 20.47 & 0.31 & 3.87 \\
\hline 2 & 100 & 30 & 52.70 & 21.01 & 24.11 & 2.17 & 3.06 \\
\hline 2 & 100 & 40 & 50.89 & 20.38 & 22.91 & 5.82 & 3.11 \\
\hline 2 & 100 & 60 & 50.54 & 20.96 & 23.47 & 5.03 & 3.05 \\
\hline 2 & 100 & 70 & 52.33 & 22.08 & 24.10 & 1.49 & 3.09 \\
\hline
\end{tabular}

$\left(\mathrm{Al}^{3+}\right)$ shows stronger resistance against acid attack compared with divalent alkali metals $\left(\mathrm{Ca}^{2+}, \mathrm{Mg}^{2+}\right)$.

In summary, leaching conditions need to be rationally chosen for obtaining a high leaching ratio of elemental $\mathrm{Ca}, \mathrm{Mg}$ and $\mathrm{Al}$, low elemental selectivity for $\mathrm{Si}$ and a suitable $n\left(\mathrm{M}^{2+}\right) /$ $n\left(\mathrm{M}^{3+}\right)$. Leaching conditions comprising $2 \mathrm{M}$ acid concentration, $100{ }^{\circ} \mathrm{C}$ leaching temperature, 90 min leaching time and a S/L ratio of $40 \mathrm{~g} \mathrm{~L}^{-1}$ allowed a high leaching ratio of $\mathrm{Ca}, \mathrm{Mg}$ and $\mathrm{Al}$ to be achieved, at $88.08 \%, 88.59 \%$ and $82.27 \%$, respectively, $5.82 \%$ of Si and a value of 3.11 for $n\left(\mathrm{M}^{2+}\right) / n\left(\mathrm{M}^{3+}\right)$.

\subsection{Characterization of CaMgAl-LDHs sorbent}

Fig. 5(a) shows the XRD pattern of as-synthesized CaMgAlLDHs. All the sharp reflections with a high-degree of crystallinity were attributed to the successful formation of LDHs. The LDHs showed obvious crystallographic changes as a result of calcination at different temperatures in air. The sample maintained hydrotalcite structure when the calcination temperature was $200{ }^{\circ} \mathrm{C}$. Once calcined at $400{ }^{\circ} \mathrm{C}$, the sample showed weak reflections characteristic of hydrotalcite with a small amount of periclase, indicating decomposition of the layered structure. Calcination above $800{ }^{\circ} \mathrm{C}$ generated new crystalline phases assignable to $\mathrm{CaO}, \mathrm{MgO}$ and mayenite $\left(\mathrm{Ca}_{12} \mathrm{Al}_{4} \mathrm{O}_{33}\right)$. The thermal events of as-synthesized CaMgAl-LDHs from BFS was further studied by TGA analysis. The thermal decomposition of the CaMgAl-LDHs occurred in three main weight loss steps (ESI, Fig. S1 $\dagger$ ). In addition, this LDHs had a nominal structural formula of $\mathrm{Ca}_{1.89} \mathrm{Mg}_{0.89} \mathrm{Al}_{1.0}(\mathrm{OH})_{7.5} \mathrm{Cl}_{0.83}\left(\mathrm{CO}_{3}\right)_{0.11} \cdot y \mathrm{H}_{2} \mathrm{O}$, and most of the intercalated anions were $\mathrm{Cl}^{-}$(ESI, Table S1 $\dagger$ ).

The textural properties obtained from BET analysis are presented in Fig. 5(b). The specific surface area increased with increase in calcination temperature from $200{ }^{\circ} \mathrm{C}$ to $400{ }^{\circ} \mathrm{C}$. The sample after calcination at $400^{\circ} \mathrm{C}$ for $4 \mathrm{~h} \mathrm{had}$ a specific surface area of $38.55 \mathrm{~m}^{2} \mathrm{~g}^{-1}$, which was twice as large as that of the LDHs. A slight increase in average pore diameter and pore volume were also observed. When the temperature further increased to $800{ }^{\circ} \mathrm{C}$, the crystallisation of resulting oxides resulted in a decreased surface area and porosity.

SEM micrographs of as-synthesized LDHs calcined at different temperatures are shown in Fig. 6. Fig. 6(a) shows the formation of a typical plate-like structure with well-defined hexagonal shape. ${ }^{16}$ The particle size of LDHs was about $1 \mu \mathrm{m}$ and the thickness was less than $40 \mathrm{~nm}$. Fig. 6(b) shows that the plate-like particles stacked together after calcination at $200^{\circ} \mathrm{C}$. When the temperature further increased, calcination resulted in the disappearance of characteristic LDHs features with the formation of amorphous

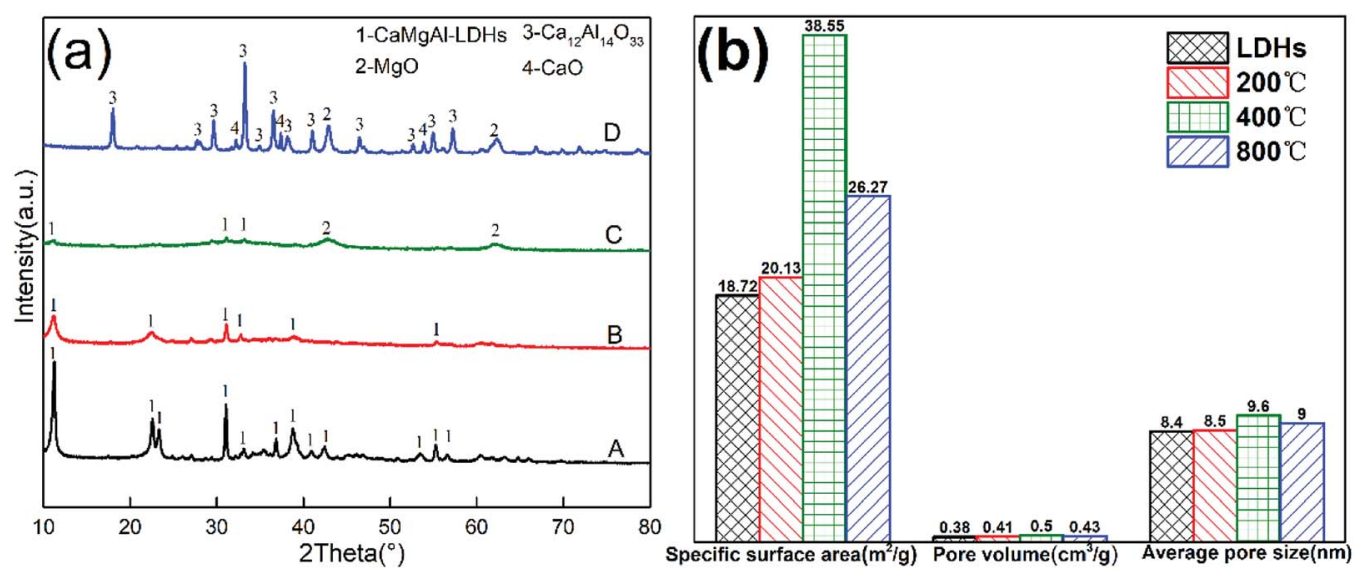

Fig. 5 (a) X-ray diffraction patterns of LDHs calcined at different temperatures for $4 \mathrm{~h}$ : (A) as-synthesized, (B) $200^{\circ} \mathrm{C},(\mathrm{C}) 400^{\circ} \mathrm{C}$ and (D) $800^{\circ} \mathrm{C}$ (b) BET results of $\mathrm{LDH}$ calcined at different temperatures. 
mixed oxides (Fig. 6(c)), which further developed into mineral crystallites as a consequence of sintering events (Fig. 6(d)). ${ }^{17}$

\subsection{Characterization of MCM-41 sorbent}

The SEM image in Fig. 7(a) shows that the as-synthesized mesoporous silica nanoparticles on a scale of less than $200 \mathrm{~nm}$ had a good dispersity, with some coalescence into aggregates. The TEM micrograph in Fig. 7(b) reveals a highly ordered 2D hexagonal pore structure array of the MCM-41 type silica; this feature was also confirmed by the presence of (100), (110) and (200) plane reflections in Fig. $7(\mathrm{c}) .^{18}$ The diameter between the fringes of the pore in the mesoporous structure was estimated to be around $3 \mathrm{~nm}$, which is in good agreement with the BJH pore size distribution analysis in Fig. $7(\mathrm{~d})$, having a primary distribution in the range of $2.6-2.8 \mathrm{~nm}$. The sorption isotherm in Fig. 7(d) shows a type IV isotherm according to the IUPAC classification with a sharp increase step in the relative pressure region of $0.31-0.35$. This was attributed to capillary condensation within the narrow distribution of mesopores. ${ }^{19}$

Textural properties of MCM- 41 including BET surface area $\left(S_{\mathrm{BET}}\right)$, total pore volume $\left(V_{\mathrm{p}}\right)$, average pore radius $\left(D_{\mathrm{BJH}}\right)$ and the wall thickness $\left(b_{\mathrm{p}}\right)$ are shown in Table 4 . This material had a surface area of $1270 \mathrm{~m}^{2} \mathrm{~g}^{-1}$, much higher than when synthesized from fly ash $\left(732 \mathrm{~m}^{2} \mathrm{~g}^{-1}\right),{ }^{20}$ iron ore tailings $\left(527 \mathrm{~m}^{2}\right.$ $\left.\mathrm{g}^{-1}\right),{ }^{21}$ sodium silicate $\left(874 \mathrm{~m}^{2} \mathrm{~g}^{-1}\right)^{22}$ and pure TEOS $\left(1100 \mathrm{~m}^{2}\right.$ $\left.\mathrm{g}^{-1}\right) .^{20}$ The thickness of pore walls was comparable at $1.04 \mathrm{~nm}$ with results in the previous literature. ${ }^{23}$

\subsection{Evaluation of $\mathrm{CO}_{2}$ capture performance}

The $\mathrm{CO}_{2}$ adsorption behaviour of as-synthesized $\mathrm{Ca}_{1.89} \mathrm{Mg}_{0.89^{-}}$ $\mathrm{Al}_{1.0}$-LDHs and after calcination at $200{ }^{\circ} \mathrm{C}, 400{ }^{\circ} \mathrm{C}, 800{ }^{\circ} \mathrm{C}$, denoted as CaMgAl-LDHs-200, CaMgAl-LDHs-400, CaMgAlLDHs-800, respectively, was measured at $400{ }^{\circ} \mathrm{C}$. As seen from Fig. 8(a), after calcination at $400{ }^{\circ} \mathrm{C}$ for $4 \mathrm{~h}$, CaMgAl-LDHs- 400 exhibited a first contact capacity of $1.58 \mathrm{mmol} \mathrm{g}^{-1}$, almost 2 times greater than that of CaMgAl-LDHs without thermal activation. However, calcination at $800{ }^{\circ} \mathrm{C}$ caused a great decline in the $\mathrm{CO}_{2}$ adsorption. These results were in agreement with those of Ram Reddy et al., ${ }^{25}$ indicating that there exists an optimised thermal activation temperature for CaMgAl-LDHs. The events of dehydroxylation, decomposition of intercalated anions, followed by crystallization upon thermal calcination (confirmed by the XRD and TGA analyses) gave rise to the variation in surface area and a number of active basic sites, thus having a great influence on the $\mathrm{CO}_{2}$ uptake.

The thermal stability of CaMgAl-LDHs-400 was evaluated through continuous $\mathrm{CO}_{2}$ adsorption/desorption cycles. As shown in Fig. 8(b), CaMgAl-LDHs-400 demonstrates good reusability and cyclic performance throughout the 20 adsorption/desorption cycles. After 20 times cycles, the CaMgAlLDHs-400 sorbent still adsorbs around $1.2 \mathrm{mmol} \mathrm{g}^{-1}$ of $\mathrm{CO}_{2}$ at $400{ }^{\circ} \mathrm{C}$ and $1 \mathrm{~atm}, \mathrm{CO}_{2}$ adsorption capacity reduces $24 \%$.

As depicted in Fig. 9(a), for MCM-41, the highest $\mathrm{CO}_{2}$ adsorption capacity increases from 0.95 to $1.24 \mathrm{mmol} \mathrm{g}^{-1}$ when the adsorption temperature increases from 25 to $75{ }^{\circ} \mathrm{C}$, which is a characteristic feature of physisorption processes. ${ }^{26}$ However, the adsorption capacity decreased slightly to $1.13 \mathrm{mmol} \mathrm{g}^{-1}$ when the temperature exceeded $100{ }^{\circ} \mathrm{C}$, which could be related to the dominant $\mathrm{CO}_{2}$ desorption reaction at high temperature. The adsorption/desorption cycles for MCM- 41 were conducted at $75^{\circ} \mathrm{C}$. As shown in Fig. 9(b), there was about $20 \%$ deterioration in the adsorption capacity after 20 adsorption/desorption cycles, indicating that the MCM-41 sorbents had a good thermal stability.

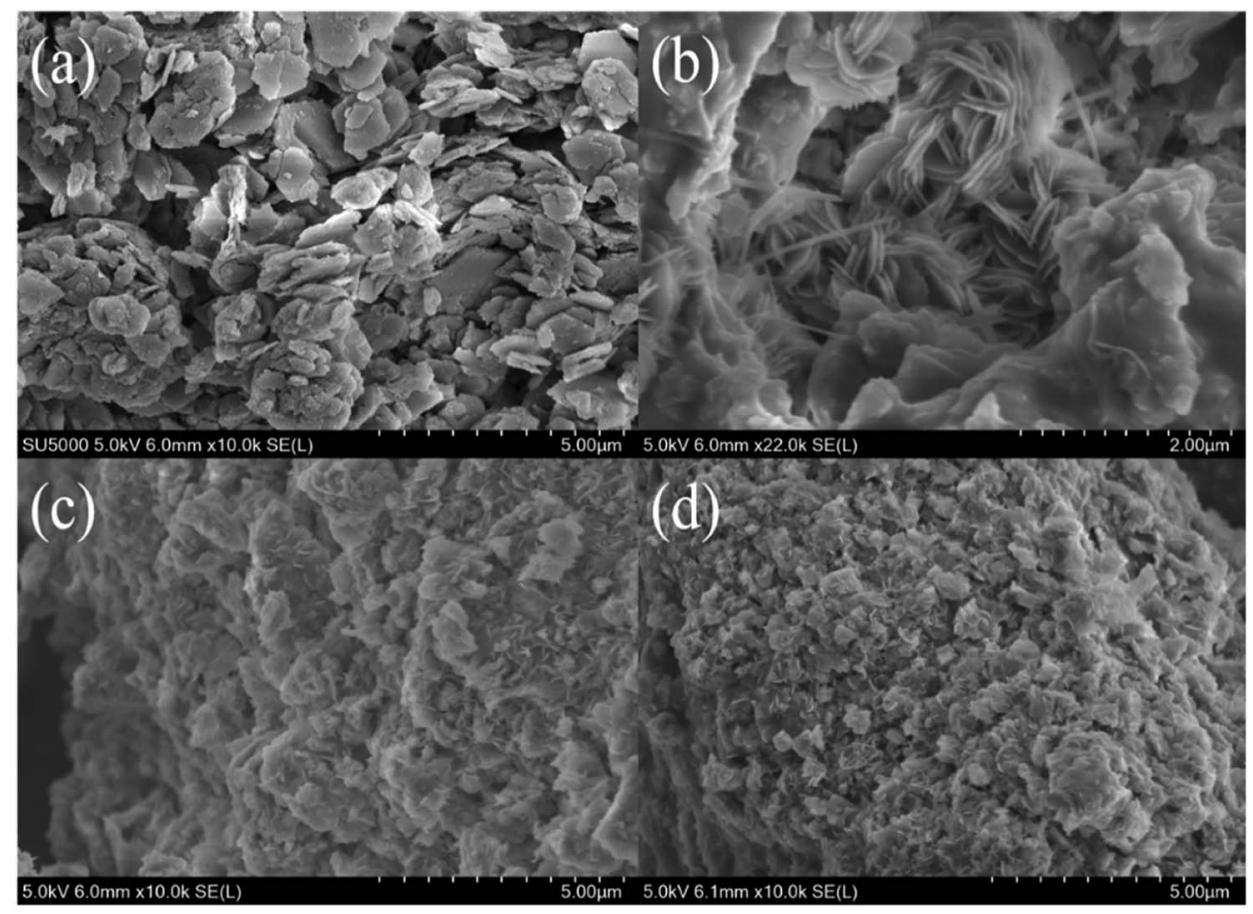

Fig. 6 SEM images of LDHs sorbents calcined at different temperatures: (a) as-synthesized, (b) $200{ }^{\circ} \mathrm{C}$, (c) $400{ }^{\circ} \mathrm{C}$ and (d) $800{ }^{\circ} \mathrm{C}$. 

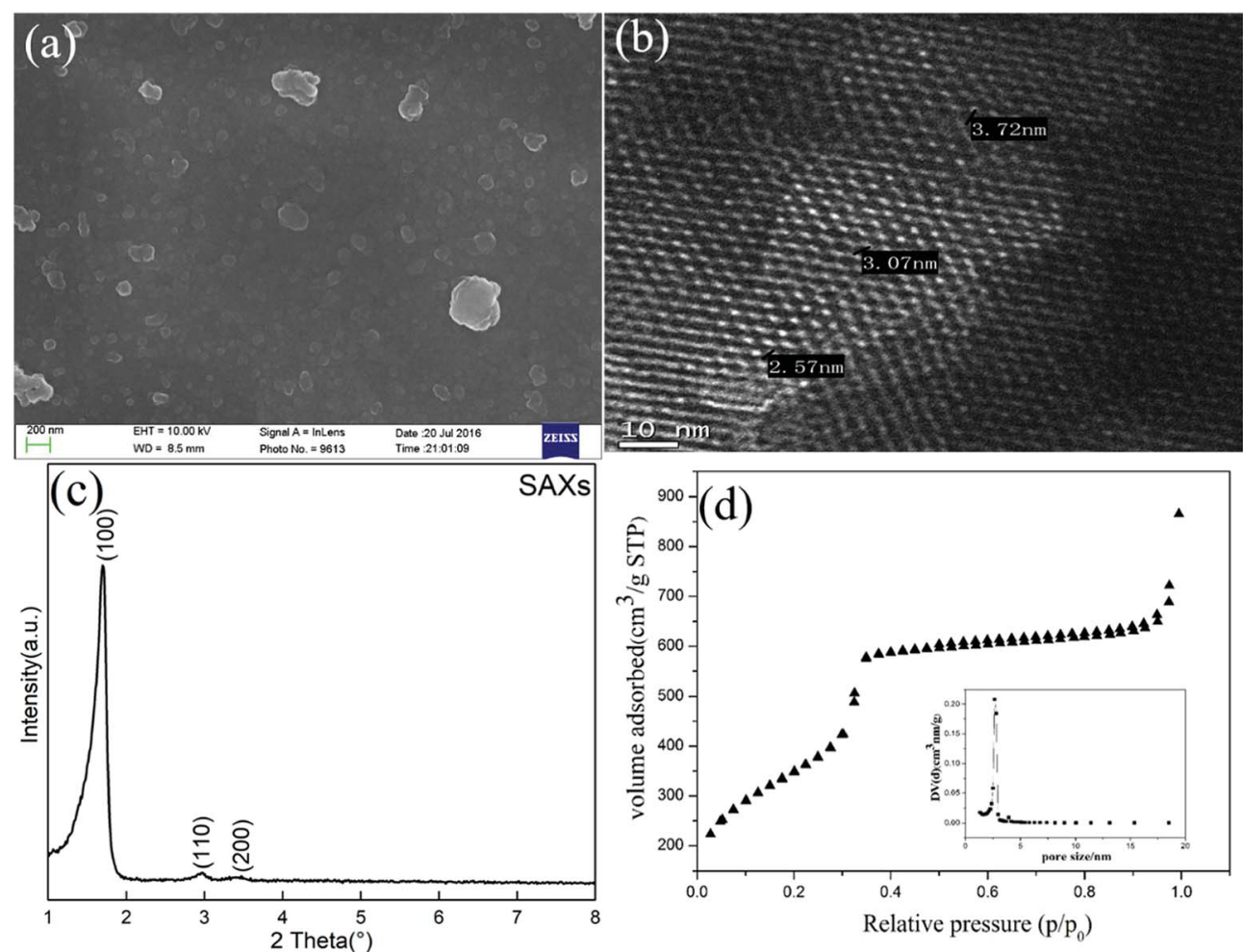

Fig. 7 (a) SEM image and (b) TEM image of MCM-41 sorbent prepared from BFS; (c) SAXs scattering pattern; (d) $\mathrm{N}_{2}$ adsorption-desorption isotherm and pore size distribution.

Table 4 Textural properties of MCM-41 derived from BFS ${ }^{a}$

\begin{tabular}{llllll}
\hline Sample & $S_{\text {BET }}\left(\mathrm{m}^{2} \mathrm{~g}^{-1}\right)$ & $V_{\mathrm{p}}\left(\mathrm{cm}^{3} \mathrm{~g}^{-1}\right)$ & $D_{\text {BJH }}(\mathrm{nm})$ & $d_{100}(\mathrm{~nm})$ & $b_{\mathrm{p}}(\mathrm{nm})$ \\
\hline MCM-41 & 1270 & 1.342 & 3.034 & 3.531 & 1.04
\end{tabular}

${ }^{a} S_{\mathrm{BET}}$, specific surface area calculated using BET equation. $V_{\mathrm{p}}$, the total pore volumes were determined at a $P / P_{0}$ value of 0.995 . $D_{\mathrm{BJH}}$, the mean pore size distributions were determined by $\mathrm{BJH}$ mode applied to the desorption branches of the isotherms. $b_{\mathrm{p}}$, the pore wall thickness, calculated from equation. ${ }^{24} b_{\mathrm{p}}=2 d_{100} / 3^{1 / 2}-D_{\mathrm{BJH}}$, where $d_{100}$ refers to the interplanar spacing of the (100) reflection by Bragg's equation $\left(2 d_{100} \sin \theta=\lambda\right)$.

\subsection{Adsorptive mechanism for the two prepared composites for $\mathrm{CO}_{2}$ capture}

The composite stability for the prepared two composites was studied using the thermogravimetric analysis with results shown in Fig. 10. LDHs-400 sample was heated to $400{ }^{\circ} \mathrm{C}$ and maintained for a while, the weight loss was small. Similarly, MCM-41 sample was heated to $700{ }^{\circ} \mathrm{C}$ and maintained for a while, the weight loss was due to the adsorbed gas and water at the beginning and did not change as the temperature rised to $700{ }^{\circ} \mathrm{C}$. This confirmed that both composites had good stability. As depicted Fig. 8(a), the LDHs calcined at $400{ }^{\circ} \mathrm{C}$ has a maximum adsorption capacity, which was most likely due to
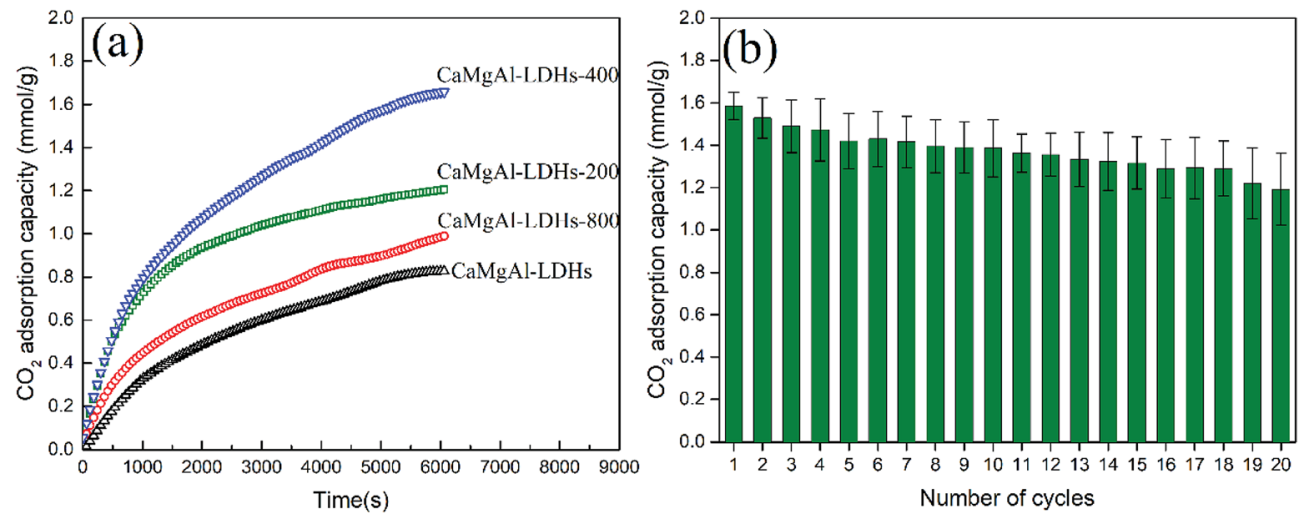

Fig. 8 (a) The effect of calcination temperature on the first $\mathrm{CO}_{2}$ contact capacities of $\mathrm{CaMgAl}-\mathrm{LDH}$ sorbents adsorption temperature was set at $400{ }^{\circ} \mathrm{C}$; (b) adsorption/desorption cycles for CaMgAl-LDHs-400 at $400{ }^{\circ} \mathrm{C}$. 

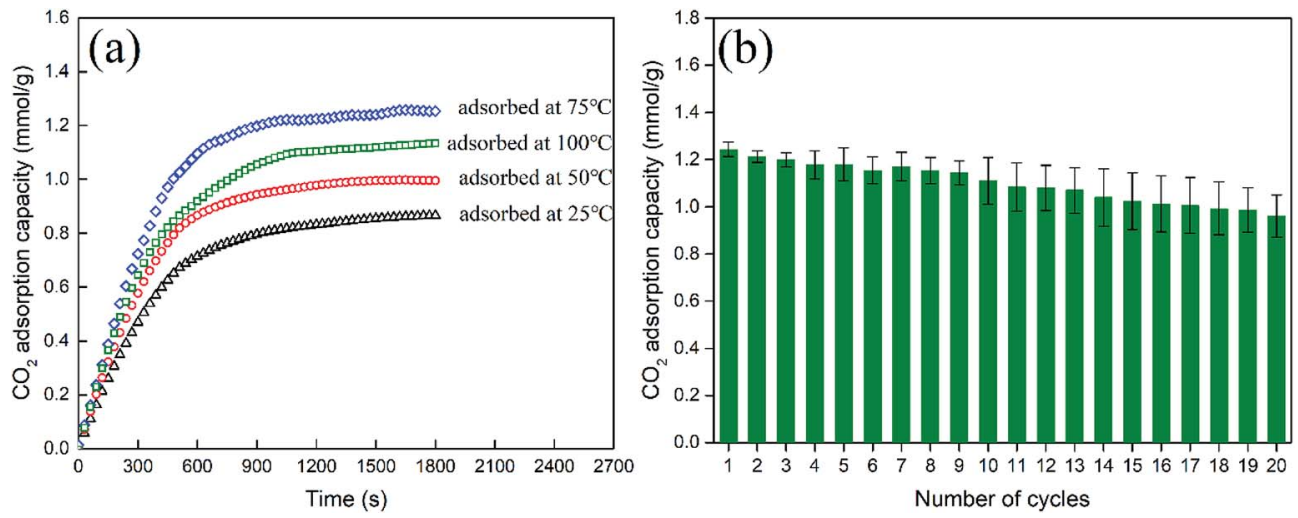

Fig. 9 (a) The first $\mathrm{CO}_{2}$ contact capacities of MCM-41 sorbent at different temperatures (b) adsorption/desorption cycles for MCM-41(adsorbed at $75^{\circ} \mathrm{C}$, desorbed at $105^{\circ} \mathrm{C}$ ).

the optimum balance between the surface area and enough basic sites. ${ }^{25}$ The BET analysis for LDHs calcined at different temperatures in Fig. 5(b) supported this theory. The LDHs-400 sample, which is an amorphous mixed oxide phase, had the maximum BET surface area compared to the other samples at $38.55 \mathrm{~m}^{2} \mathrm{~g}^{-1}$. The LDHs-200 sample had the minimum BET surface area because its layered structure was maintained, with $\mathrm{CO}_{3}{ }^{2-}$ ions occupying the basic sites. Calcination at higher temperature $\left(800{ }^{\circ} \mathrm{C}\right)$ decomposed most $\mathrm{CO}_{3}{ }^{2-}$ ions to release some basic sites for $\mathrm{CO}_{2}$ adsorption but resulted in a low BET surface area due to the phase transformation of amorphous mixed oxide into crystalline spinel, $\mathrm{CaO}$ and $\mathrm{MgO}$ phases. So, the LDHs-400 sample had not only the highest surface area but also enough basic sites for improving the $\mathrm{CO}_{2}$ adsorption performance.

FTIR spectra patterns of CaMgAl-LDHs-400 and MCM-41 before and after adsorption are shown in Fig. 11. For LDHs400 , the reflection at $1633 \mathrm{~cm}^{-1}$ for LDHs material was the $\delta \mathrm{H}_{2} \mathrm{O}$ mode of interlayer water molecules. ${ }^{27}$ The relatively weak $\mathrm{CO}_{3}{ }^{2-}$ reflection at $1425-1475 \mathrm{~cm}^{-1}$ indicated a low level of contamination with $\mathrm{CO}_{2}$ before adsorption, ${ }^{28}$ while after $\mathrm{CO}_{2}$ adsorption the corresponding band located at around $1417 \mathrm{~cm}^{-1}$ was strong. The $\mathrm{AlO}_{6}$ stretching mode with the indicative reflection around $457 \mathrm{~cm}^{-1}$ was observed after calcination. ${ }^{26}$ The new reflection at $846 \mathrm{~cm}^{-1}$ indicated the presence of $\mathrm{Ca}-\mathrm{O}$ bonding, which was consistent with previous results reported in the synthesis of hydrotalcite with varied (Ca $+\mathrm{Mg}) / \mathrm{Al}$ molar ratios. ${ }^{29}$ After $\mathrm{CO}_{2}$ adsorption, the samples exhibited extremely weak vibration peaks at $1633 \mathrm{~cm}^{-1}$ and the disappearance of other vibration peaks. The disappearance of peaks related to metal-oxygen vibrations at low wavenumber of around $500 \mathrm{~cm}^{-1}$ was due to the chemical reaction between basic sites and $\mathrm{CO}_{2}$.

For MCM-41, the band around $3450 \mathrm{~cm}^{-1}$ attributed to hydrogen bonded surface silanols ( $\mathrm{Si}-\mathrm{OH})$ and adsorbed water molecules were due to $\mathrm{O}-\mathrm{H}$ stretching and the band at $1633 \mathrm{~cm}^{-1}$ was due to bending vibrations of adsorbed water molecules. The peaks centred at $1093 \mathrm{~cm}^{-1}, 804 \mathrm{~cm}^{-1}$ and $460 \mathrm{~cm}^{-1}$ corresponded to the asymmetric stretching, symmetric stretching and rocking vibrations of the $\mathrm{Si}-\mathrm{O}-\mathrm{Si}$ bonds, respectively. The band appearing at $956 \mathrm{~cm}^{-1}$ was attributed to $\mathrm{Si}-\mathrm{O}$ stretching in $\mathrm{Si}-\mathrm{OH}$. Silanol groups ( $\mathrm{Si}-\mathrm{OH})$ on the surface of MCM-41 maybe the adsorption sites for capturing $\mathrm{CO}_{2}$ molecules. ${ }^{30}$ After $\mathrm{CO}_{2}$ adsorption, the band at $956 \mathrm{~cm}^{-1}$ disappeared and a very weak band at $1384 \mathrm{~cm}^{-1}$ was observed for the symmetric stretching mode of linear $\mathrm{CO}_{2}$ which verified that physisorbed $\mathrm{CO}_{2}$ on mesoporous silica was detected. ${ }^{31}$ The intensity of band corresponded to $\mathrm{OH}$ stretching. of free silanol groups around $3450 \mathrm{~cm}^{-1}$ decreased after $\mathrm{CO}_{2}$ adsorption and a weakly bonded adduct between silanol groups and $\mathrm{CO}_{2}:-\mathrm{OH} \cdots \mathrm{O}=\mathrm{C}=\mathrm{O}$ formed which can easily break down as the temperature increases. As depicted Fig. 9(a), the $\mathrm{CO}_{2}$
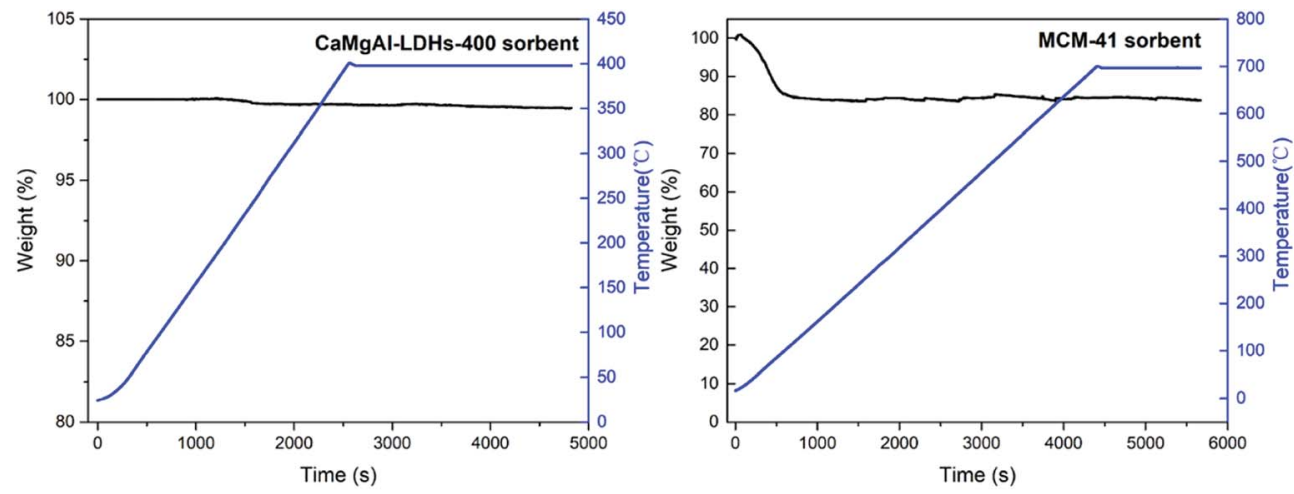

Fig. 10 Thermogravimetric analysis of CaMgAl-LDHs-400 and MCM-41. 


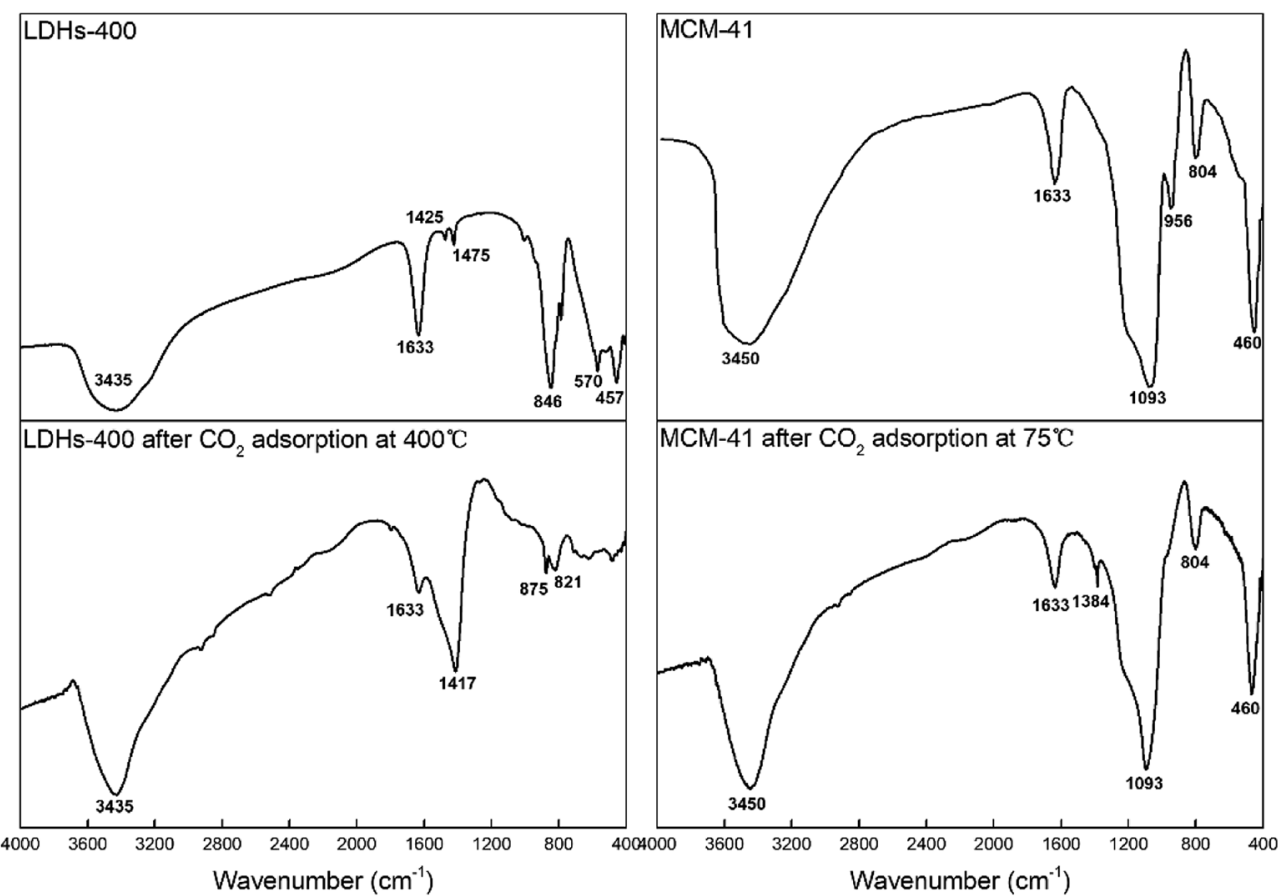

Fig. 11 FTIR spectra patterns of CaMgAl-LDHs-400 and MCM-41 before and after adsorption.

Table 5 Comparison of the $\mathrm{CO}_{2}$ adsorption capacities of various materials

\begin{tabular}{|c|c|c|c|}
\hline \multirow[t]{5}{*}{ LDHs } & $\mathrm{Mg}_{3} \mathrm{Al}$-stearate-LDH- 400 & $1.30 \mathrm{mmol} \mathrm{g}^{-1}$ at $300^{\circ} \mathrm{C}, 1 \mathrm{bar}$ & 33 \\
\hline & $\mathrm{Ca}_{3} \mathrm{Al}-\mathrm{LDH}-550$ & $0.87 \mathrm{mmol} \mathrm{g}^{-1}$ at $350^{\circ} \mathrm{C}, 1 \mathrm{bar}$ & 34 \\
\hline & $\mathrm{CaMg}_{2} \mathrm{Al}-\mathrm{LDH}-550$ & $1.28 \mathrm{mmol} \mathrm{g}^{-1}$ at $350^{\circ} \mathrm{C}, 1 \mathrm{bar}$ & 34 \\
\hline & Nano-sized $20 \mathrm{wt} \% \mathrm{~K}_{2} \mathrm{CO}_{3}$ impregnated $\mathrm{Mg}_{3} \mathrm{Al}-\mathrm{LDH}-400$ & $1.21 \mathrm{mmol} \mathrm{g}^{-1}$ at $200^{\circ} \mathrm{C}, 1 \mathrm{bar}$ & 35 \\
\hline & $\mathrm{Ca}_{1.89} \mathrm{Mg}_{0.89} \mathrm{Al}_{1.0}$-LDHs-400 & $1.66 \mathrm{mmol} \mathrm{g}^{-1}$ at $400{ }^{\circ} \mathrm{C}, 1 \mathrm{bar}$ & In this study \\
\hline & $\mathrm{MCM}-41-\mathrm{NH}_{2}$ & $1.15 \mathrm{mmol} \mathrm{g}^{-1}$ at $30^{\circ} \mathrm{C}, 2.1 \mathrm{bar}$ & 37 \\
\hline & TRI-PE-MCM-41 & $2.21 \mathrm{mmol} \mathrm{g}^{-1}$ at $55^{\circ} \mathrm{C}, 1 \mathrm{bar}$ & 38 \\
\hline & MCM-41 & $1.25 \mathrm{mmol} \mathrm{g}^{-1}$ at $75^{\circ} \mathrm{C}, 1 \mathrm{bar}$ & In this study \\
\hline
\end{tabular}

adsorption capacity at higher temperature $\left(100^{\circ} \mathrm{C}\right)$ decreased because interaction between $\mathrm{CO}_{2}$ and silanol groups is van der Waals force, which does not favor the adsorption at higher temperatures. ${ }^{32}$

\subsection{Comparison of the $\mathrm{CO}_{2}$ adsorption capacities of various materials}

Different kinds of LDHs and mesoporous silica and their $\mathrm{CO}_{2}$ adsorption performances are compared in Table 5 . The maximum $\mathrm{CO}_{2}$ adsorption capacity of CaMgAl-LDHs derived from BFS is $1.66 \mathrm{mmol} \mathrm{g}^{-1}$, which is higher than that of other LDHs synthesized using pure reagents. The maximum $\mathrm{CO}_{2}$ adsorption capacity of MCM-41 derived from BFS was $1.25 \mathrm{mmol} \mathrm{g}^{-1}$, which is comparable to other mesoporous silica synthesized from other materials. Comparing the results of this study with those reported in literature, BFS was found to be a promising raw material for CaMgAl-LDHs and MCM-41 production and their further use as efficient sorbents for capturing $\mathrm{CO}_{2}$.

\section{Conclusions}

In this work, the conversion of blast furnace slag into two different kinds of promising sorbents of $\mathrm{CO}_{2}$ has been presented. The calcium, magnesium, aluminium in BFS were selectively extracted by hydrochloric acid and used for preparation of layered double hydroxides (LDHs). The leaching residue which contained a high amount of silica was utilised for MCM-41 material synthesis. Several operating variables including initial hydrochloric acid concentration, leaching temperature, solid-to-liquid ratio, and leaching time were optimised. It was found that higher hydrochloric acid concentration, higher leaching temperature, and longer leaching time could promote silica gel formation; this provided a great 
advantage for the selective leaching out of calcium, magnesium, aluminium with high efficiency. Characterisation of the assynthesized CaMgAl-LDHs and MCM-41 sorbents was performed to determine chemical composition, morphology and textural properties. The structural formula of CaMgAl-LDHs was determined as $\mathrm{Ca}_{1.89} \mathrm{Mg}_{0.89} \mathrm{Al}_{1.0}(\mathrm{OH})_{7.5} \mathrm{Cl}_{0.83}\left(\mathrm{CO}_{3}\right)_{0.11} \cdot y \mathrm{H}_{2} \mathrm{O}$, with $\mathrm{Cl}^{-}$as the predominate intercalated anion. Thermal calcination at $400{ }^{\circ} \mathrm{C}$ enhanced the specific surface area, thus leading to improved $\mathrm{CO}_{2}$ uptake and a maximum $\mathrm{CO}_{2}$ adsorption capacity of $1.58 \mathrm{mmol} \mathrm{g}^{-1}$ at $400{ }^{\circ} \mathrm{C}$. The MCM- 41 sorbents derived from BFS exhibited a high surface area of $1270 \mathrm{~m}^{2} \mathrm{~g}^{-1}$ and showed comparable $\mathrm{CO}_{2}$ adsorption capacity with a value of $1.24 \mathrm{mmol} \mathrm{g}{ }^{-1}$ at $75{ }^{\circ} \mathrm{C}$. In the $\mathrm{CO}_{2}$ adsorption/desorption cycles, both sorbents showed good reusability and cyclic performance. With all these results, the CaMgAl-LDHs and MCM-41 sorbents derived from blast furnace slag are promising sorbents for practical applications in the field of $\mathrm{CO}_{2}$ capture.

\section{Conflicts of interest}

There are no conflicts to declare.

\section{Acknowledgements}

The National Natural Science Foundation of China (No. 51574169, No. 51604178, No. 51704202, No. 51604202, No. 51774209), the Natural Science Foundation of the Jiangsu Higher Education Institutions of China (No. 17KJB450002), are duly acknowledged for their financial support. The authors also are grateful for the analysis support from Soochow University.

\section{References}

1 S. Lee, J. W. Kim, S. Chae, J. H. Bang and S. W. Lee, J. CO2 Util., 2016, 16, 336-345.

2 S. Teir, S. Eloneva, C. J. Fogelholm and R. Zevenhoven, Energy, 2007, 32, 528-539.

3 S. Eloneva, S. Teir, J. Salminen, C. J. Fogelholm and R. Zevenhoven, Energy, 2008, 33, 1461-1467.

4 S. Eloneva, S. Teir, J. Salminen, C. J. Fogelholm and R. Zevenhoven, Ind. Eng. Chem. Res., 2008, 47, 7104-7111.

5 S. Eloneva, S. Teir, J. Savolahti, C. Fogelholm and R. Zevenhoven, Proceeding ECOS 2007, Padova, Italy, 2007, vol. II, pp. 1389-1396.

6 C. Hall, D. J. Large, B. Adderley and H. M. West, Miner. Eng., 2014, 65, 156-162.

7 A. jun Xu, H. ning Zhang, Y. Yang, J. Cui, D. feng He and N. yuan Tian, J. Iron Steel Res. Int., 2012, 19, 34-38.

8 J. H. Bang, S. W. Lee, C. Jeon, S. Park, K. Song, W. J. Jo and S. Chae, Energies, 2016, 9(12), 996.

9 W. Bao, H. Li and Z. Yi, Ind. Eng. Chem. Res., 2010, 49, 20552063.

10 J. Wang, L. Huang, R. Yang, Z. Zhang, J. Wu, Y. Gao, Q. Wang, D. O'Hare and Z. Zhong, Energy Environ. Sci., 2014, 7, 3478-3518.

11 S. H. Wang, Y. Bin Wang, Y. M. Dai and J. M. Jehng, Appl. Catal., A, 2012, 439-440, 135-141.
12 S. Tian, J. Jiang, F. Yan, K. Li, X. Chen and V. Manovic, Green Chem., 2016, 18, 4022-4031.

13 Y. Kuwahara and H. Yamashita, ISIJ Int., 2015, 55, 15311537.

14 K. Song, S. Park, W. Kim, C. Jeon and J.-W. Ahn, Metals, 2017, 7, 199.

15 Q. Wang and D. Ohare, Chem. Rev., 2012, 112, 4124-4155.

16 A. P. Tathod and O. M. Gazit, Cryst. Growth Des., 2016, 16, 6709-6713.

17 A. C. Vieira, R. L. Moreira and A. Dias, J. Phys. Chem. C, 2009, 113, 13358-13368.

18 K. Flodström and V. Alfredsson, Microporous Mesoporous Mater., 2003, 59, 167-176.

19 P. Selvam, S. K. Bhatia and C. G. Sonwane, Ind. Eng. Chem. Res., 2001, 40, 3237-3261.

20 H. Misran, R. Singh, S. Begum and M. A. Yarmo, J. Mater. Process. Technol., 2007, 186, 8-13.

21 H. Yu, X. Xue and D. Huang, Mater. Res. Bull., 2009, 44, 21122115.

22 Y. Y. Zhou, X. xuan Li and Z. xing Chen, Powder Technol., 2012, 226, 239-245.

23 P. Kumar, N. Mal, Y. Oumi, K. Yamana and T. Sano, J. Mater. Chem., 2001, 11, 3285-3290.

24 D. Zhao, Q. Huo, J. Feng, B. F. Chmelka and G. D. Stucky, J. Am. Chem. Soc., 1998, 120, 6024-6036.

25 M. K. Ram Reddy, Z. P. Xu, G. Q. Lu and J. C. D. Da Costa, Ind. Eng. Chem. Res., 2006, 45, 7504-7509.

26 R. L. Frost, H. J. Spratt and S. J. Palmer, Spectrochim. Acta, Part A, 2009, 72, 984-988.

27 R. Galindo, A. López-Delgado, I. Padilla and M. Yates, Appl. Clay Sci., 2014, 95, 41-49.

28 A. Boumaza, L. Favaro, J. Lédion, G. Sattonnay, J. B. Brubach, P. Berthet, A. M. Huntz, P. Roy and R. Tétot, J. Solid State Chem., 2009, 182, 1171-1176.

29 J. Zhou, Z. P. Xu, S. Qiao, Q. Liu, Y. Xu and G. Qian, J. Hazard. Mater., 2011, 189, 586-594.

30 W. Wang, J. Li, X. Wei, J. Ding, H. Feng, J. Yan and J. Yang, Appl. Energy, 2015, 142, 221-228.

31 Z. Bacsik, N. Ahlsten, A. Ziadi, G. Zhao, A. E. Garcia-Bennett, B. Martín-Matute and N. Hedin, Langmuir, 2011, 27, 1111811128.

32 T. Witoon and M. Chareonpanich, Songklanakarin J. Sci. Technol., 2012, 34, 403-407.

33 Q. Wang, H. H. Tay, Z. Zhong, J. Luo and A. Borgna, Energy Environ. Sci., 2012, 5, 7526-7530.

34 P. W. Xiao, J. Y. Jun, J. Cheng, P. H. Zheng and P. X. Zhi, Environ. Sci. Technol., 2008, 42, 614-618.

35 Q. Wang, Y. Gao, J. Luo, Z. Zhong, A. Borgna, Z. Guo and D. O'Hare, RSC Adv., 2013, 3, 3414-3420.

36 M. Bhagiyalakshmi, L. J. Yun, R. Anuradha and H. T. Jang, J. Porous Mater., 2010, 17, 475-484.

37 M. R. Mello, D. Phanon, G. Q. Silveira, P. L. Llewellyn and C. M. Ronconi, Microporous Mesoporous Mater., 2011, 143, 174-179.

38 Y. Belmabkhout, R. Serna-Guerrero and A. Sayari, Adsorption, 2011, 17, 395-401. 